\title{
The Position and Causes of Students Errors in Algebraic Thinking Based on Cognitive Style
}

\section{Arief Agoestanto}

Mathematics Education Study Program of Universitas Negeri Semarang, Indonesia, arief.mat@mail.unnes.ac.id

\section{Y. L. Sukestiyarno}

Mathematics Education Study Program of Universitas Negeri Semarang, Indonesia, yarno.2009@yahoo.com

\section{Isnarto}

Mathematics Education Study Program of Universitas Negeri Semarang, Indonesia, isnarto.math@mail.unnes.ac.id

\section{Rochmad}

Mathematics Education Study Program of Universitas Negeri Semarang, Indonesia, rahmad_manden@yahoo.com

\section{D. Lestari}

Mathematics Education Study Program of Universitas Negeri Semarang, Indonesia, mahardikadwilestari@yahoo.co.id

$$
1
$$

The purpose of this research was to describe the positions and causes of students' errors in algebraic thinking based on the cognitive style. This study was qualitative research with subject consisting of twelve students. The results showed that (1) students with Field Independent type tended to make errors at the stage of comprehension, transformation, and process skills while students with Field Dependent type tended to make errors at the stage of comprehension, transformation, process skills, and encoding; and (2) the causes of errors were the students' incomprehension that related to the purpose of the problem, the lack of understanding that related to mathematical modelling, the lack of students' accuracy, the students' inaccuracy of using knowledge to convert an equations to the equivalent equation, student's inability to calculate the solution of an equations, students deviated from the formula that they used before and the students' incomprehension that related to the unit of measurement in mathematics.

Keywords: algebraic thinking, causes of error, cognitive style, positions of error, error

Citation: Agoestanto, A., Sukestiyarno, Y. L., Isnarto, Rochmad, \& Lestari, M. D. (2019). The Position and Causes of Students Errors in Algebraic Thinking Based on Cognitive Style. International Journal of Instruction, 12(1), 1431-1444. https://doi.org/10.29333/iji.2019.12191a 


\section{INTRODUCTION}

One of mathematics field that is taught in schools is algebra. Understanding the basic concepts of algebra is essential because it will be a superior prior knowledge when students learn material that involves algebra in the later stages. Almost all fields of mathematics require algebra as a problem-solving tool. According to Usiskin (2010), the algebraic thinking is important because algebra basically is one of the conceptions that was used as a problem-solving tool. According to Gibson (2014), algebra is the beginning of a journey that provides the skill to solve more complex problems.

As Windsor (2010) says that algebra is vital because it can expand the thinking to solve concrete problems by using abstraction and operation on mathematical entities logically and independently from the real world. The algebraic thinking is also a key for students of their mathematical achievement and scientific knowledge (Greens in Ontario Ministry of Education, 2013).

Due to its significant uses, algebra is used as one of the content dimensions domains that exists in the implementation of Trends in International Mathematics and Science Study (TIMSS) (Balitbang, 2011). Based on results of TIMSS in 2011, Indonesia ranked 38 out of 42 countries for mathematics achievement. (Mullis et al., 2012: 114). It needs attention especially educators in Indonesia though.

Further, algebra is one of the components in National Mathematics Examination in Indonesia. However, the fact shows that the result of students' National Mathematics Examination is still low. This evident comes from the results of UN (National Examination) at Junior High School 1 Bae Kudus in the academic year 2015/2016 which shows that mathematics subjects get an average of 46.82. In fact, it is lower than the result of UN academic year 2014/2015 which is 52.03. If this problem is solved, then it will inhibit students to learn mathematics on the next stage including algebra material.

According to Keiran (2004), there are three capabilities in algebraic thinking; generational skill, transformational skill, and global meta-level skill. First, generational skill is a skill that involves algebraic forms and equations such as equations containing unknown in problem representation, forms of geometric patterns and number sequences, and form of rules governing numerical relationships. Second, transformational skill is a skill that includes factorization, algebraic expansion, substitution, addition and multiplication of polynomial forms, a solution of equations, simplification of algebraic forms, solving equivalent forms and equations. Third, global meta-level skill is the skill to use algebra as a problem-solving tool, mathematical problem modeling, relating to the properties of algebraic structures, generalizations of operation, change analysis, relationship analysis, predictor tools, justification tools and mathematical proofs.

Kieran's opinion about algebraic thinking skills had been widely embraced by other researchers in the field of Algebra, such as Johanning (2004), Nobre et al. (2011), Eisenmann \& Even (2011), Tabach et al. (2012) and Tam \& Thang (2014). Thus, this study adopts the three types of algebraic skills that are proposed by Kieran (2004) as the basis for measuring students' algebraic thinking. 
Considering the importance of algebraic thinking skill to master, the errors made by students can inhibit them in expanding their thinking to solve concrete problems. Meanwhile, in order to minimalize the errors not repeated continuously, it is necessary to hold an analysis of the position and causes of students' algebraic thinking error. One of the error analysis methods used is Newman's error analysis. Newman in White (2009) classifies the errors made by students into five types: (1) Reading Error, (2) Comprehension Error, (3) Transformation Error, (4) Process Skill Error, and (5) Encoding Error. If one of the stages is not fulfilled by students, it will result in errors which cause students' answers deviate from it should be.

Furthermore, a learning outcome is also influenced by the characteristics of students, one of them is student's cognitive style. Winkel (1996) proposes the notion of cognitive style as the typical way which is used to observe and do mental activity in the cognitive field, which is individually, often unconsciously and persist. This suggests that the cognitive style cannot be manipulated, it means that a person with a certain cognitive style undoubtedly finds difficulties to change into other cognitive styles. According to Chrysostomou et al. (2011), there are some types of cognitive style; (1) visual-verbal, (2) impulsive and reflective, and (3) Field Independent (FI) and Field Dependent (FD). In this study, the types of cognitive style used are Field Independent (FI) and Field Dependent (FD) delivered by Witkin (1971).

Shi (2011) states that the selection of learning strategies for students is strongly influenced by their cognitive style. Again, Moussa (2014) argues that the understanding of student characteristics in every dimension will also increase learning process.

Based on the description above, the purposes of this research are (1) to describe the position of students' error in algebraic thinking based on the cognitive style and (2) to describe the causes of students' errors in the algebraic thinking based on their cognitive styles.

\section{METHOD}

\section{Research Design}

This research used a qualitative research method with grounded theory approach. Creswell (2004) explains that grounded theory approach allowed the researchers to go deeper into the problem under the research.

\section{Research Subjects}

The research was conducted at SMP 1 Bae Kudus in the academic year 2016/2017. The subjects were the students from class VIII-H that consists of twelve students taken from two students in high, medium, and low group for each type of students' cognitive style.

\section{Data Collection Tools}

The data collection tools in this research were tests and interviews. The test consisted of two types: Group Embedded Figures Test (GEFT) and algebraic thinking test. Group Embedded Figures Test (GEFT) was developed by Witkin (1971), and it was used for 
grouping cognitive style types based on psychological differences in field-independent cognitive style (FI) and field-dependent cognitive style (FD). The algebraic thinking test was in the form of subjective (essay) as much as 5 items used to know students' algebraic thinking as well as the position of their errors on the generational, transformational, and global meta-level.

The interview used was an unstructured interview in which the researcher did not use interview guidance which had been arranged wholly and systematically (Sugiyono, 2015). The purpose of the interview was to describe the student's errors in algebraic thinking and the causes of errors from each research subject. After the data were obtained, then they were analyzed qualitatively.

\section{Data Analysis}

Qualitative data analysis was used to describe the positions and causes of errors in algebraic thinking based on the cognitive style. Sugiyono (2015) explains that the qualitative data analysis technique consists of three stages of analysis. They are data reduction, display data, and data verification

\section{Reliability and Validity}

Credibility data was done by persistent observation; the researcher interviewed the subject carefully and continuously in detail and repeated the questions at a different time for the unclear or different information. Data validation was done by triangulation: comparing the data of students' written test results with interview data, and also comparing and examining data from different subjects in one cognitive style. Meanwhile the transferability was done by describing in detail the positions and causes of algebraic thinking errors of each subject. Furthermore, dependability was done by audit method that maintained the honesty and accuracy of the researcher's perspective. While the criteria of confirmability were met because the analyzed data were the data which were explored and studied the truth.

\section{FINDINGS}

\section{The Position of Students' Errors in Algebraic Thinking Based on Cognitive Style}

The result of Group Embedded Figures Test (GEFT) was shown at Figure 1. 


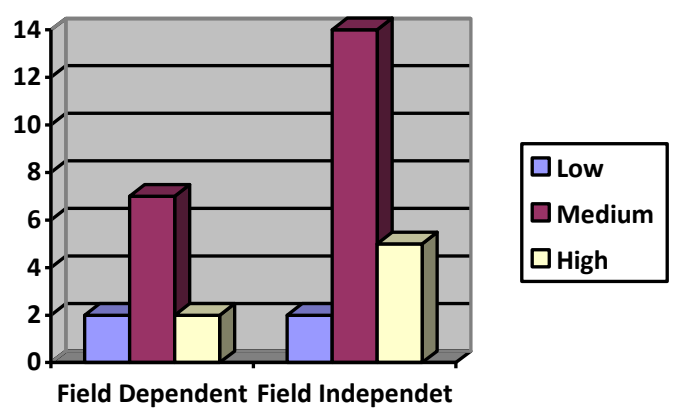

Figure 1

The Result of Group Embedded Gigures Test (GEFT)

From the Result of GEFT, we choose 2 students with low FD type, 2 students with medium FD type, 2 students with high FD type, 2 students with low FI type, 2 students with medium FI type, and 2 students with high FI type. The data is shown at Table 1.

Table 1

Research Subjects

\begin{tabular}{ll}
\hline Research Subjects Code & Cognitive Style \\
\hline FDR_1 & Low FD \\
FDR_2 & Low FD \\
FDS_1 & Medium FD \\
FDS_2 & Medium FD \\
FDT_1 & High FD \\
FDT_2 & High FD \\
FIR_1 & Low FI \\
FIR_2 & Low FI \\
FIS_1 & Medium FI \\
FIS_2 & Medium FI \\
FIT_1 & High FI \\
FIT_2 & High FI \\
\hline
\end{tabular}

For completing an essay test of algebraic thinking with the material area and volume of cubes and cuboids, the series of steps and systematic steps are needed. One of the procedures that can be used in solving mathematics problems in the form of a description is by using Newman procedure. Based on the results, it is found that there was no subject who made a major error in the reading stage. Yet the new major error starts in the stage of comprehension. Further, the errors were different for each type of cognitive style subjects. Table 2 presents error analysis results of the research subject to Field Independent (FI) cognitive style. 
Table 2

The Result of Error Analysis of Research Subject with Field Independent (FI) Cognitive Style

\begin{tabular}{clllllll}
\hline No & Subject & \multicolumn{4}{c}{ Error Accumulation } & \multicolumn{2}{l}{ Tendency } \\
& & R & C & T & P & E & \\
\hline 1 & FIR_1 & 0 & 1 & 1 & 1 & 0 & Comprehension, Transformation, Process Skill \\
2 & FIR_2 & 0 & 1 & 0 & 1 & 0 & Comprehension, Process Skill \\
3 & FIS_1 & 0 & 0 & 1 & 1 & 0 & Transformation, Process Skill \\
4 & FIS_2 & 0 & 0 & 1 & 1 & 0 & Transformation, Process Skill \\
5 & FIT_1 & 0 & 0 & 0 & 0 & 0 & - \\
6 & FIT_2 & 0 & 0 & 1 & 0 & 0 & Transformation \\
\hline
\end{tabular}

Notes:

R: Number of Reading's Error

P: Number of Process Skill's Error

C: Number of Comprehension' Error

E: Number of Encoding's Error

$\mathrm{T}$ : Number of Transformation's Error

While Table 3 presents the results of error analysis of research subject with Field Dependent (FD) cognitive style.

Table 3

The Results of Error Analysis of Research Subject with field dependent (FD) Cognitive Style

\begin{tabular}{clcccccl}
\hline No & Subject & \multicolumn{9}{c}{ Error Accumulation } & \multicolumn{1}{l}{ Tendency } \\
& & $\mathrm{R}$ & $\mathrm{C}$ & $\mathrm{T}$ & $\mathrm{P}$ & $\mathrm{E}$ & \\
\hline 1 & FDR_1 & 0 & 1 & 1 & 1 & 1 & $\begin{array}{l}\text { Comprehension, Transformation, Process } \\
\text { Skill, Encoding }\end{array}$ \\
& & & & & & & $\begin{array}{l}\text { Process Skill } \\
3\end{array}$ \\
& FDR_2 & 0 & 0 & 1 & 2 & 0 & Transformation, Process Skill \\
4 & FDS_1 & 0 & 0 & 1 & 1 & 0 & Transformation, Process Skill \\
5 & FDS_2 & 0 & 0 & 1 & 1 & 0 & Encoding \\
6 & FDT_1 & 0 & 0 & 0 & 0 & 1 & Encoding \\
\hline
\end{tabular}

Notes:

R: Number of Reading's Error

P: Number of Process Skill's Error

C: Number of Comprehension' Error

E: Number of Encoding's Error

T: Number of Transformation's Error

In general, it can be seen that the errors in each type of cognitive style have different tendencies. The data listed in Table 2 and Table 3 can be summarized as presented in following table.

Table 4

Error Tendency in Each Cognitive Style

No Cognitive Style Type Tendency

$1 \quad$ Field Independent(FI) Comprehension, Transformation, and Process Skill

2 Field Dependent(FD) Comprehension, Transformation, Process Skill, and Encoding

Causes of Research Subjects Errors with Field Independent Cognitive Style

In this research, 6 students with field independent (FI) cognitive style were selected which consist of three levels: 2 students of low field independent, two students of 
medium field independent, and 2 students of high field independent. The six students were FIR_1, FIR_2, FIS_1, FIS_2, FIT_1, and FIT_2. In brief, based on the results of data analysis, students with FI cognitive style tended to make a major error in Comprehension, Transformation, and Process Skill stage.

First, in Comprehension stage, there were two subjects that made error: FIR_1 and FIR_2. Both subjects made a mistake in item number 5. Basically, a transformation error was indicated by the lack of students' understanding of the purpose of the problem related to change. The cause of the error was students' incomprehension about the purpose of the given problem.

Second, in the transformation stage, there were four subjects who made an error. They made errors in item 3 and 5. For item 3, subjects who made error were FIR_1, FIS_1, and FIS_2. For item 5, only FIT_2 made a mistake. Basically a transformation error was indicated by the lack of students' ability to determine the right strategy after they understood the problem. These errors include: (a) an error in making a mathematical model of a given problem and (b) an error in determining the formula used. The cause of this error was the students' incomprehension about the implementation of cubes area material in mathematical modeling and also the lack of students' accuracy in their work. Therefore, they deviated from the problem.

The other findings in this research were four students with FI cognitive-style who still did the wrong process skill. They were: FIR_1, FIR_2, FIS_1, and FIS_2. They made an error in item 3. Basically the error of the skill process was indicated by the students' lack to determine the right strategy after they understood the problem. These errors included (a) error in converting equations into equivalent equations, (b) error in substituting, and (c) error in computing the solution of an equation. The causes of these errors were the lack of students' accuracy in working on the problem, students' inaccuracy in using knowledge to convert an equation into the equivalent equation, and students' inability in calculating the solution of an equation.

Overall, the types and the causes of students' error in FI cognitive style were in accordance with the characteristic of people with FI cognitive style according to Anwar (2014), people with FI cognitive style tended to impose the structure they have on information presented in ambiguous or unstructured format. This characteristic led the students with FI cognitive-style type to make an error during mathematical modeling and algebraic calculation.

Indeed, the error analysis result at one of research subject with independent field type: FIR_1, when solving algebra problem is presented in Figure 2.

Question:

Andi has 3 rubrik's cube. Five times the surface area first rubik equals to $7 \mathrm{~cm}^{2}$ more than two times the surface area of second rubik. Two times the surface area of second rubik plus the surface area of third rubik equals to $10 \mathrm{~cm}^{2}$. The surface area of third rubik equals to $4 \mathrm{~cm}^{2}$ less than two times the surface area of first rubik. Determine the edge of the three cubes! 

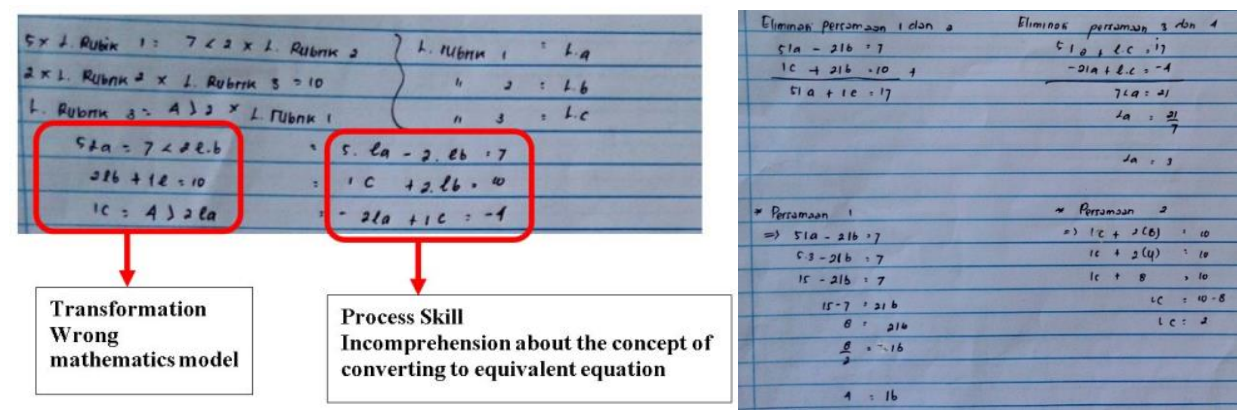

Figure 2

Written Work Result of FIR_1

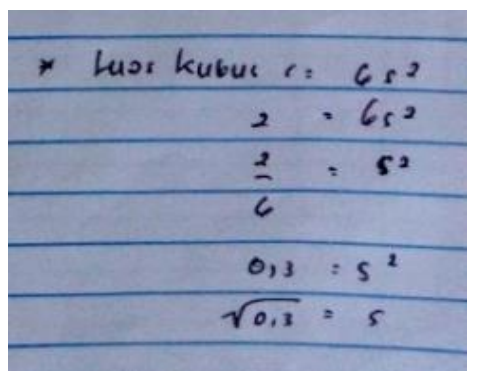

Figure 3

Continued Written Work Result of FIR_1

Based on the results of written work of FIR_1 in Figure 3, the errors were categorized into the error of comprehension, transformation, and process skill. The work of FIR_1 in more detail is presented in Table 4.

Table 4

Work Result Analysis of FIR_1

\begin{tabular}{|c|c|c|}
\hline No & Error Type & Reason / Explanation \\
\hline 1 & Comprehension & $\begin{array}{l}\text { FIR_1 wrote down completely the known information but did not } \\
\text { write down the asked questions. } \\
\text { FIR_1 wrote down the necessary variable. }\end{array}$ \\
\hline 2 & Transformation & $\begin{array}{l}\text { FIR_1 was wrong in making a mathematical model of the problem. } \\
\text { FIR_1 was able to write the formula of cubes area. }\end{array}$ \\
\hline 3 & Process Skill & $\begin{array}{l}\text { FIR_1 was suddenly able to write that equation of } 5 \mathrm{~L}_{\mathrm{a}}=7<2 \mathrm{~L}_{\mathrm{b}} \text { can be } \\
\text { converted into } 5 \mathrm{~L}_{\mathrm{A}}-2 \mathrm{~L}_{\mathrm{B}} \text {. } \\
\text { FIR_ } 1 \text { was able to calculate the area of the third cube by the process } \\
\text { of elimination and substitution. } \\
\text { FIR_ } 1 \text { was able to calculate the length of the third cube side by } \\
\text { substituting } \mathrm{L}_{\mathrm{c}}=2 \text { to the rubric area } \mathrm{C}=6 \mathrm{~s}^{2} \text {. }\end{array}$ \\
\hline
\end{tabular}

\section{Causes of Error of Research Subject with Field Dependent Cognitive Style}

In this research, 6 students with field dependent (FD) cognitive style who were previously selected consisted of three levels: two students of the low dependent field, 
two students of the medium-dependent field, and two students of the high dependent fields. The six students were FDR_1, FDR_2, FDS_1, FDS_2, FDT_1, and FDT_2. Based on the results, students with FD cognitive style tended to make major mistakes in the Comprehension, Transformation, Process Skill, and Encoding.

In Comprehension stage, there was only one subject who made an error, FDR_1. The error was in item 5. Basically the transformation error was indicated by the lack of students' comprehension about the purpose of the problem related to the change. The cause of the error was students' incomprehension about the purpose of the given problem.

Meanwhile, in the transformation stage, there were four subjects who made errors. They made errors in item 3 and 5. For item 3, subjects who made errors were FDR_1, FDR_2, and FDS_2. For item 5, there was only one person, FDS_1. The errors included (a) error in generating a mathematical model of a given problem and (b) error in determining the formula used. The causes of this error were the lack of students' understanding about the implementation of cubes area material in mathematical modeling and the lack of students' accuracy in their work. Therefore, they are deviated by the problem. This result was in accordance with the characteristics of people with FD cognitive style according to Anwar (2014). He notes that people with FD cognitive style tend to accept the existing structure because their lack of skill to restructure and tend to more experience difficulties in abstracting relevant information from additional instruction in harder study problem.

Furthermore, the other findings in this research were four students with FD cognitivestyle who still did the wrong process skill. They made errors in item 3 and 5. For item 3 , subjects who made error were FDR_1, FDR_2, FDS_1, and FDS_2. For item 5 was only one person, FDR_2. The errors included: (a) error in converting an equation into equivalent equation, (b) error in substituting, and (c) error in calculating, then error in determining the solution of an equation. The causes of this error were the lack of students' accuracy in working on the problem, the students' inaccuracy in using knowledge to convert an equation into the equivalent equation, and the students' inability in determining the solution of an equation.

In addition, students with FD cognitive styles also made encoding errors. There were three subjects; they made an error in item 2 and 4. For item 2, only FDT_2 that made a mistake. For item 4. there were FDR_1 and FDT_1. The errors included errors in writing and expressing conclusions and also errors in writing suitable mathematical units. The cause of this errors were students deviated by the formula they used before and students' incomprehension about the unit of measurement in mathematics.

The eror analysis result at one of research subject with field dependent type: FDR_1 when solving algebra problem is presented in Figure 4.

Question:

Andi has 3 rubrik's cube. Five times the surface area first rubik equals to $7 \mathrm{~cm}^{2}$ more than two times the surface area of second rubik. Two times the surface area of second 
rubik plus the surface area of third rubik equals to $10 \mathrm{~cm}^{2}$. The surface area of third rubik equals to $4 \mathrm{~cm}^{2}$ less than two times the surface area of first rubik. Determine the edge of the three cubes!
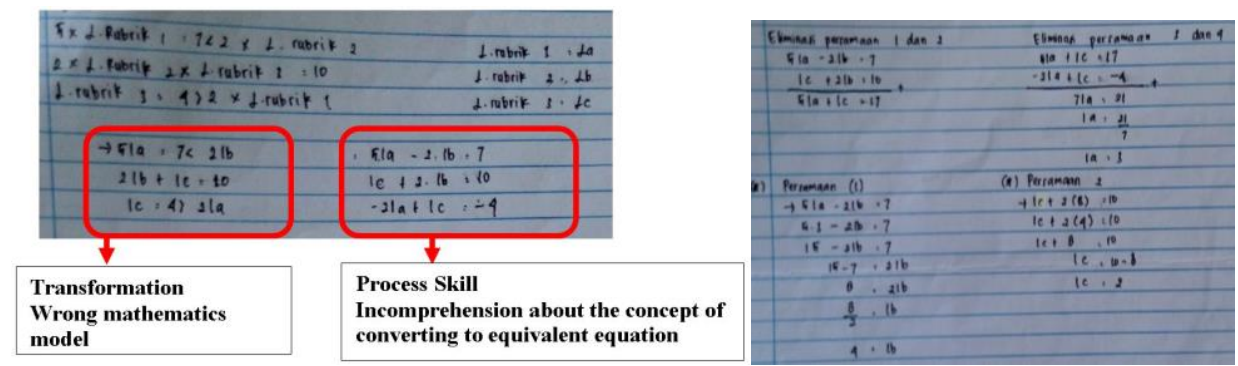

Figure 4

Written Work Result FDR_1

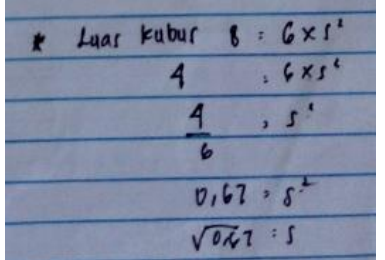

Figure 5

Continued Written Work Result FDR_1

The written work result of FDR_1 above could be categorized as the comprehension, transformation, process skill, and encoding error. The work result of FDR_1 in more detail is presented in Table 5 .

Table 5

Work FDR_1

\begin{tabular}{|c|c|c|}
\hline No & Error Type & Reason / Explanation \\
\hline 1 & Comprehension & $\begin{array}{l}\text { FIR_1 wrote down completely the known. } \\
\text { FIR_1 did not write down the asked questions. } \\
\text { FIR_1 wrote down the necessary variable. }\end{array}$ \\
\hline 2 & Transformation & $\begin{array}{l}\text { FIR_1 was wrong in making a mathematical model of the problem. } \\
\text { FIR_1 was able to write the formula of cubes area. }\end{array}$ \\
\hline 3 & Process Skill & $\begin{array}{l}\text { FIR_1 was suddenly able to write that equation of } 5 \mathrm{~L}_{\mathrm{a}}=7<2 \mathrm{~L}_{\mathrm{b}} \text { could } \\
\text { be converted into } 5 \mathrm{~L}_{\mathrm{A}}-2 \mathrm{~L}_{\mathrm{B}}=7 \text {. } \\
\text { FIR_1 was able to calculate the area of the third cube by the process } \\
\text { of elimination and substitution. } \\
\text { FIR_ } 1 \text { was able to calculate the length of the third cube side by } \\
\text { substituting } \mathrm{L}_{\mathrm{C}}=2 \text { to the rubric area } C=6 \mathrm{~s}^{2} \text {. }\end{array}$ \\
\hline 4 & Encoding & $\begin{array}{l}\text { FDR_1 did not write the conclusion of the problem. } \\
\text { FDR_1 did not write the measurement unit in the final work result. }\end{array}$ \\
\hline
\end{tabular}

International Journal of Instruction, January $2019 \bullet$ Vol.12, No.1 
Based on the research results, it was found that students with FI cognitive style made errors in Comprehension, Transformation and Process Skill. In the Comprehension stage, Level-Meta Global skill was not mastered with indicators capable of using algebra to analyze changes. In the Transformation stage, Level-Meta Global skill was not mastered with indicators capable of using algebra as mathematical modeling. At the Process Skill stage, students' Transformational skill was not mastered with the indicator capable of converting equation into equivalent equations, do substitution process, and determine the solution of an equation.

Then, students with FD cognitive style had error tendency in Comprehension, Transformation, Process Skill, and Encoding stages. In the Comprehension stage, LevelMeta Global skill was not mastered with indicators capable of using algebra to analyze changes. As well as in the Transformation stage, it was not mastered with indicators capable of using algebra as mathematical modeling. While in the Process Skill stage, Transformational skill was not mastered with the indicator capable of converting equation to equivalent equations, to do substituting process, and determine the solution of an equation. The last, in the Encoding stage, Generational skill was not mastered with the indicator capable to determine the meaning of solution from an equation.

Conversely, the results were in accordance with research conducted by Agoestanto et al. (2017) which indicates that students with FI cognitive style were better than students with FD cognitive style. This was an evident from some aspects of critical thinking that have been studied. Students with FI cognitive style tended to have errors in aspects of assumptions and interpretation of information in critical thinking skills. In the assumption aspect, students' errors took place in doing the operation of algebraic form that is multiplication and subtraction. In interpreting information aspect, students' error with FI cognitive style occurred in determining the solution of a linear equation system. Owing to the facts, there is relevance to the position of students with FI cognitive style error that is at the stage of Process Skill in which the student did not master one of the indicators in Transformational skill that is determining the solution of an equation.

As the research that was conducted by Agoestanto (2017) highlights that students with FD Cognitive Style tended to have errors in aspects of conclusion, assumption, and interpreting information in critical thinking skills. In the aspect of drawing conclusion, students with FD cognitive-style are not able to formulate a mathematical conclusion in a correct sentence. In the aspect of assumptions and interpreting information, students with FD cognitive-style experience errors in performing algebraic form operations on a linear equation system, therefore, the solution is not appropriate. Eventually, there was relevance to the position of students' error with FD cognitive style that was in the stage of Process Skill. They did not master one indicator in the Transformational skill that was to solve an equation and in the Encoding stage. It means that they did not master one of the indicators in Generational skill that was able to determine the meaning of solution from an equation.

Regarding to above explanation, the writer concluded that FI and FD students have different errors in algebraic thinking. In this research, algebraic thinking skill of each student was influenced by their own cognitive style. In line with this research, Wilkie 
and Clarke (2016 reveal that algebraic thinking of each student is influenced by visualization and method of its own generalization. Again, Raharjo (2017) says that the independence of learning affects algebraic thinking. It shows that the higher the independence of learning, the better the result of algebraic thinking skill is. This was in line with the research results that students with FI cognitive style have fewer errors in working on the problem of algebraic thinking skills than students with FD cognitive style. In other words, students who were more dependent on one thing will have lower algebraic thinking skills than independent students. Eroglu and Tanisli (2017) also explain that different ways of algebraic thinking are the result of various questions given to students. Therefore, for further research, the writer suggested that the teachers also have the potential role to develop algebraic thinking from appropriate questions for each student characteristic.

Moreover, Onyekuru's research (2015) reveals that someone with Field Independent cognitive style had better achievements in science, while the Field Dependent cognitive style had better achievements in the arts. Above all, Mathematics is part of science. Thus, Field Independent students are better than Field Dependent students on algebraic thinking skills. Again, Khoury (2013) explains that students with Field Independent cognitive style tended to be able to determine the media and supporters of learning appropriately. This was also supposed to help an Independent Field student has higher algebraic thinking than the Dependent Field one.

\section{CONCLUSION}

Based on the results and discussions, it can be concluded that the students with Field Independent (FI) cognitive style tend to make the main errors in the stage of comprehension, transformation, and skill process, while the students with Field Dependent (FD) cognitive style tend to make the main errors in the stage of comprehension, transformation, process skill, and encoding.

Firstly, in the Comprehension stage, students' algebraic thinking which was not mastered was the Level-Meta Global skill with indicator: capable of using algebra to analyze changes. Secondly, in the Transformation stage, students' algebraic thinking which was not mastered was Level-Meta Global skill with indicator: capable of using algebra as mathematical modeling. Thirdly, in the Process Skill, stage students' algebraic thinking which was not mastered was Transformational skill with the indicators: capable of converting equation into equivalent equations, substitute the process, and determine the solution of an equation. Fourthly, in the Encoding stage, students' algebraic thinking which was not mastered was in Generational skill with the indicator: capable of determining the meaning of solution from an equation.

However, the causes of error in the Comprehension stage was students' incomprehension about the purpose of the given problem. The causes of the errors in the transformation stage were the lack of students' understanding of the implementation of cubes area material on mathematical modeling and the lack of students' accuracy in working. Therefore, they can be deceived by the problem. Then, the causes of the errors in the process skill stage were the lack of students' accuracy in working on the problem, the 
students' inaccuracy in using knowledge to convert equation into the equivalent equation, and the students' inability to calculate the solution of an equation. While the causes of errors at the encoding stage were students who are deviated from the formula they used before and the student's incomprehension about the unit of measurement in mathematics.

Afterwards, there are some suggestions that can be contributed to the results of this research, as follows (1) teacher should more often give mathematical problems that require interpretation of language so the errors of FI and FD students in the stage of comprehension and transformation can be minimized, (2) the modeling of the algebra problem and its operations need to be emphasized in algebra learning so that student errors of type FI and FD on the process skill stage can be minimized, and (3) FD students typically need emphasis on the units of measurement that are used in mathematics so that errors in the encoding stage can be minimized.

\section{REFERENCES}

Agoestanto, A., Sukestiyarno, Y. L., \& Rochmad. (2017). Analysis of Mathematics Critical Thinking Students in Junior High School Based on Cognitive Style. Journal of Physics: Conference Series 824(1), 1-6.

Anwar, K. (2014). Proses Berpikir Peserta didik SMP Gaya Field Independent Dan Field Dependent Dalam Pemodelan Matematika. (Master's Thesis). Universitas Negeri Semarang. Semarang.

Chrysostomou, M., Tsingi, C., Cleanthous, E., \& Pantazi, D. P. (2011). Cognitive Style and their relation to number sense and algebraic reasoning. Proceedings of the Seventh Congress of the European Society for Research in Mathematics Education (Polandia).

Creswell, J. W. (2014). Research Design: Pendekatan Kualitatif, Kuantitatif, dan Mixed. Yogyakarta: Pustaka Pekajar.

Eisenmann, T. \& Even, R. (2011). Enacted Types of Algebraic Activity in Different Classes Taught by the Same Teacher. International Journal of Science and Mathematics Education , 9, 867-891.

Eroğlu, D., \& Tanışlı, D. (2017). An integration of algebraic habits of mind into classroom practice. Elementary Education Online , 16(2), 566-583.

Gibson, J. (2014). Why Learn Algebra? Retrieved from http://www. mathgoodies.com/articles/ why_learn_algebra.html.

Johanning, D.I. (2004). Supporting the Development of Algebraic Thinking in Middle School: a Closer Look at Students' Informal Strategies. Journal of Mathematical Behavior , 23, 371-388.

Khoury, A. G. (2013). A field-independent view of field-independence. Theory and Practice in Language Studies , 3(6), 885. 
Kieran, C. (2004). Algebraic Thinking in the Early Grades: What Is It?. Mathematics Educator, 8(1), 139-151.

Mullis,S.V.I.,Martin, O.M., Foy, M., \& Arora, A. (2012). TIMSS 2011 International Results in Mathematics. United States: TIMSS \& PIRLS International Study Center. Retrieved from http://timssandpirls.bc.edu/timss2011/downloads/ T11_IR_Mathematics _FullBook.pdf.

Nobre, S., Escola E.B., Amado, N., Carreira,S.,\& Pedro da Ponte, J. (2011). Algebraic Thinking of Grade 8 Students in Solving Word Problems With a Spreadsheet. CERME 7, 521-531.

Ontario Ministry of Education. (2013). Paying Attention to Algebraic Reasoning. Retrieved from https://ontariomathresources.ca.

Onyekuru, B. U. (2015). Field Dependence-Field Independence Cognitive Style, Gender, Career Choice and Academic Achievement of Secondary School Students in Emohua Local Government Area of Rivers State. Journal of Education and Practice, 6(10), 76-85.

Sugiyono. (2015). Metode Penelitian Pendidikan (Pendekatan Kuantitatif, Kualitatif dan $R \& D$ ). Bandung: Alfabeta, $\mathrm{CV}$.

Tam, D.\& Thang, N.C. (2014). Fostering the Ability of Teaching School Algebra for Teachers of Mathematics. Proceedings of the 7thInternational Conference on Educational Reform Innovations and Good Practices in Education: Global Perspectives.

Usiskin, Z. (2010). Doing Algebra in Grades K-4. Teaching Children Mathematics, 3(1), 346-356.

White, A. L. (2009). Diagnostic and Pedagogical Issues with Mathematical Word Problems. Brunei International Journal of Science and Mathematics Education, l(1), 100-112.

Wilkie, K. J., \& Clarke, D. M. (2016). Developing students' functional thinking in algebra through different visualisations of a growing pattern's structure. Mathematics Education Research Journal, 28(2), 223-243.

Windsor, W. (2010). Algebraic Thinking: A Problem Solving Approach. In Shaping the future of mathematics education Proceedings of the 33rd annual conference of the Mathematics Education Research Group of Australia.

Winkel, W. S. (1996). Psikologi Pendidikan dan Evaluasi Belajar. Jakarta: Gramedia.

Witkin, H. A. (1971). A Manual For The Embedded Figure Test. California: Consulting Psychologist Press. 